\title{
Differential Bone Preservation and Human Foraging at the Early Epipaleolithic Site of Tor at-Tareeq (WHS1065) in the Western Highlands of Jordan
}

\author{
Siavash Samei ${ }^{a,}{ }^{*}$, Natalie D. Munro ${ }^{a}$, Maysoon al-Nahar ${ }^{b}$, Deborah I. Olszewski ${ }^{c}$ \\ ${ }^{a}$ Department of Anthropology, 354 Mansfield Rd., Unit 1176, University of Connecticut, CT \\ 06269, USA \\ ${ }^{\mathrm{b}}$ Institute of Archaeology, University of Jordan, Amman 28170, Jordan \\ c Department of Anthropology, Penn Museum, University of Pennsylvania, 3260 South St., \\ Philadelphia, PA 19104, USA
}

*Corresponding author: siavash.samei@uconn.edu

\section{Abstract}

Three decades of archaeological investigation in the upper and lower horizons of the Early Epipaleolithic occupation at the site of Tor at-Tareeq (WHS1065) in the western highlands of Jordan have suggested that occupation intensity co-varied with climatic shifts at the end of the Last Glacial Maximum. The faunal record is a sensitive indicator of site occupation intensity, and allows us to further investigate diachronic change in human settlement at the site. Overall, preservation is of special concern, as it appears to have differentially impacted the faunal assemblages and may have influenced behavioral interpretations. Therefore, we apply a taphonomic analysis to the faunal assemblage from the 2012 excavation to investigate the nature and causes of the destruction of bones in each horizon. Our approach reveals differential destruction of the two faunal assemblages, although these did not impact the broad behavioral signatures from each horizon. Finally, we apply the prey choice model of behavioral ecology to test hypotheses for changing occupation intensity throughout the Early Epipaleolithic occupation. The study reveals an efficient subsistence strategy targeting higher-ranked adult ungulates and slow-moving tortoises, and attests to a stable low-intensity occupation across the two horizons.

Keywords: Taphonomy, Zooarchaeology, Diachronic analyses, Behavioral ecology, Site occupation intensity 


\section{Introduction}

Late Pleistocene climatic and environmental shifts have played crucial roles in shaping hunter-gatherer foraging and settlement strategies in the southern Levant (Bar-Yosef, 1990; Byrd and Garrard, 1990; Nadel and Hershkovitz, 1991; Kuhn et al., 1996; Henry, 1997; Stiner et al., 1999, 2000; Stiner, 2001; Stiner and Munro, 2002; Weiss et al., 2004; Stiner, 2005; Stutz et al., 2009). Three decades of archaeological inquiry at the Epipaleolithic site of Tor at-Tareeq (WHS1065) has enabled the study of the impacts of climatic change on foraging behavior in a steppic semi-arid environment in the western highlands of Jordan. Archaeological investigations of the Early Epipaleolithic deposits at the site of Tor at-Tareeq have revealed two occupation horizons, corresponding to different climatic regimes during a dynamic period of climate change at the end of the Last Glacial Maximum (LGM). Lithic evidence suggests differences in the intensity of the two horizons, which has been interpreted as a response to climatic and environmental change (Clark et al., 1988; Neeley et al., 1997, 1998, 2000; Olszewski et al., 2001; Olszewski and al-Nahar, 2014).

Faunal remains offer a sensitive indicator of site occupation intensity (Munro, 2004, 2009; Munro et al., this volume) and are thus imperative to holistic studies of climatic impacts on hunter-gatherer foraging and settlement strategies. Nevertheless, earlier studies at Tor at-Tareeq (e.g. Clark et al., 1988) and field observations in 2012 suggest that the faunal remains are not well preserved, particularly in the upper horizon. Differential destruction of bones can erase zooarchaeological markers of site occupation intensity and other important behavioral changes through time. Therefore, zooarchaeological analyses of temporal change in human behavior require a rigorous taphonomic investigation of formation histories.

In this paper, we use several taphonomic analyses to investigate the nature and causes of differential bone destruction between the two Early Epipaleolithic horizons, and to reconstruct the taphonomic histories of the two occupations. Taphonomic analyses allow us to study the potential impact of differential bone preservation on zooarchaeological markers of human behavior from each horizon. After accounting for taphonomy, we test the hypothesis of differential site occupation intensity at Tor at-Tareeq.

\section{Theoretical Approach for Behavioral Analysis}


We use the prey choice model from behavioral ecology to investigate site occupation intensity at Tor at-Tareeq. The prey choice model assumes that foragers will maximize net benefits when foraging, as a way to maximize reproductive fitness (MacArthur and Pianka, 1966; Stephens and Krebs, 1986; Winterhalder, 1986). Foragers maximize benefits through the preferential selection of high-ranked game, which are taxa with the highest caloric return for the energy invested in search and handling. High-ranked taxa should always be targeted on encounter. Less profitable, lower-ranked taxa are added to the diet in order of descending rank when the return rate of higher-ranked taxa declines to the point that they are equal to or lower than that of lower-ranked prey types. The encounter rate with high-ranked taxa is expected to decrease as a site's occupation intensity increases (for a detailed discussion of parameters and assumptions of the model see Charnov, 1976; Winterhalder, 1986). Site occupation intensity is a combination of several factors, including length of stay, frequency of visits, and population size (Munro, 2004; Olszewski and al-Nahar, this volume). The influence of a site's inhabitants on

local resources increases as occupation intensifies (Hames, 1980; Tchernov, 1993), so that encounter with high-ranked game should be highest when occupation intensity is low.

Archaeologists use two primary criteria to rank taxa. The first criterion is body size, with larger animals, such as aurochs and equids, ranked higher than smaller ungulates such as gazelles. In the southern Levant all ungulates rank higher than small-bodied prey such as hare, tortoise and partridge (Broughton, 1994; Nagaoka, 2001; Munro, 2004; Lupo, 2007; Broughton et al., 2011). Adult individuals also rank higher than smaller, juvenile individuals of the same species. The second criterion is procurement cost, which becomes especially important in the case of small-bodied game that differ little in their overall returns (Stiner et al., 2000; Stiner and Munro, 2002; Munro, 2004, 2009). Small game, such as tortoises, move slowly, and thus their capture requires little cost. They are ranked higher than fast-moving taxa of similar body-size. Hunting fast game such as birds and hare is energetically more costly, and requires investment in more sophisticated technologies.

\section{The Site}

Tor at-Tareeq (WHS1065) is situated on the northern bank of one of Wadi al-Hasa's tributaries, Wadi al-Ruwaq, in Jordan's western highlands, at an altitude of $815 \mathrm{~m}$ a.s.1. (Fig. 1) (MacDonald et al., 1983; Neeley et al., 1997, 2000). The site covers a surface area of about 812 
$\mathrm{m}^{2}$, although actual site size is ca. $225 \mathrm{~m}^{2}$ (Fig. 2) (Clark et al., 1988; Neeley et al., 1997,1998). It lies atop a 10 to 20 meter-high Precambrian and Cambrian limestone bedrock spur that overlooks the basin of Pleistocene wetlands (Winer, 2010), which Schuldenrein and Clark (1994, 2001) have interpreted as a lake context. The site rests on eroded paludal marls and it is situated on a $16^{\circ}$ northwest-southeast gradient (Vita-Finzi, 1966; Neeley et al., 2000). Geological, climatic, and botanical settings of Tor at-Tareeq and the Wadi al-Hasa during the Epipaleolithic period have been discussed in detail elsewhere (Schuldenrein and Clark, 1994; Neeley et al., 1997, 1998; Winer, 2010; Olszewski and al-Nahar, this volume; Ramsey and Rosen, this volume).

\subsection{Excavation History}

Burton MacDonald first located Tor at-Tareeq in 1982, during a survey of the south bank of Wadi al-Hasa (MacDonald et al., 1983). The site was first excavated by Geoffrey Clark in 1984 and 1992 (Clark et al., 1987, 1988, 1992; Neeley et al., 1997, 1998, 2000). In 1984 the team opened a 1x44 m trench that crosscut the site on its north-south axis. The trench consisted of 5meter sections labeled A through I (now called Areas A through I). In 1992, two 2x2 m squares were opened in Areas B and C (Fig. 3). Deborah Olszewski renewed excavations at the site in 2000 (Olszewski et al., 2000, 2001), and again in 2012 with Maysoon al-Nahar as part of the Western Highlands Early Epipaleolithic Project (WHEEP) (Olszewski and al-Nahar, 2014, this volume). This paper presents the Early Epipaleolithic fauna from the 2012 season. The Middle Epipaleolithic fauna from the 2000 season is published in Olszewski et al. (in press).

\subsection{Occupational Sequence}

Tor at-Tareeq has a complex stratigraphy. Archaeological deposits extend to a maximum of $1.6 \mathrm{~m}$ (average of around $1 \mathrm{~m}$ ), and are concentrated near the top of the slope. The lower twothirds of the site contain deposits that were transported downslope from their original in-situ position by erosion and colluviation (Clark et al., 1988; Neeley et al., 1997).

Cultural deposits from Areas A and B date to the Early Epipaleolithic. In Area C, Early Epipaleolithic deposits are overlain by a Middle Epipaleolithic occupation. Several charcoal

specimens from the Early Epipaleolithic deposits of Areas A, B, and C have been dated to between 21,780 and 18,270 cal. BP (Clark et al., 1988; calibrated using IntCal13, OxCal 4.2). 
Charcoal from a 1992 hearth in Area B yielded an Early Epipaleolithic date of 20,800-19,490 cal. BP (Neeley et al., 2000). The Middle Epipaleolithic occupation has not been dated, but its lithic technology is similar to that from Phase D of Kharaneh IV in the Azraq region of Jordan (Muheisen, 1988; Olszewski and al-Nahar, 2014). An ephemeral Pre-Pottery Neolithic B occupation is also evidenced by the recovery of several Neolithic arrowheads from Areas A and C (Olszewski and Schurmans, 2007; Olszewski and al-Nahar, 2014).

Lithic analyses from the 1984, 1992, and 2000 seasons point to two Early Epipaleolithic horizons at the site (Neeley et al., 2000; Olszewski et al., 2001; Olszewski and al-Nahar, 2014). The lower horizon is interpreted as the product of repeated short-term visits during a relatively cool and dry period. Subsequent climatic amelioration following the LGM may have enabled lengthier visits in the upper horizon, judging by high frequencies of reduced cores, endscrapers, and burins, which suggest a greater range of activities indicative of longer-term occupations (Neeley et al., 1997, 2000). Radiocarbon dates from Epipaleolithic contexts suggest that the occupation of these two horizons coincide with the dynamic climatic regime at the end of the LGM (Clark et al., 1988).

Olszewski and al-Nahar (2012; see also al-Nahar and Olszewski, this volume) reached a similar conclusion based on their analysis of the 2012 lithic assemblage. Characteristics of the lithic assemblages suggest that the Early Epipaleolithic deposits can be divided into an upper and a lower horizon (Table 1). The upper horizon, which corresponds to natural Layer 3, is characterized by a higher proportion of cores, endscrapers and burins, as well as La Mouillah and Qalkhan points relative to the lower horizon (Neeley et al., 2000; Olszewski and al-Nahar, 2012, 2014). The lower horizon corresponds to natural Layers $4,4 c, 5$, and $5 \mathrm{c}$, and is characterized by a higher frequency of small bladelets and non-geometric microliths, which are diagnostic of occupation in the cooler and drier period at the end of the LGM. Fewer cores, a less diverse toolkit, and more use of the microburin technique to make microliths also hint at shorter-term visits in this horizon (Neeley et al., 1997, 2000; Olszewski and al-Nahar, 2012; al-Nahar and Olszewski, this volume). Our behavioral analysis investigates whether or not these divisions are visible in the faunal record.

\subsection{Excavation Methods of the 2012 Season}


To increase horizontal exposure of the Early Epipaleolithic occupation, ten 1x1 m units were excavated in Area A. Also, to establish the spatial limits of the site, one new unit was opened eight meters to the east of the Area A excavation (S97). All units were divided into 50x50 cm quartiles. Natural sedimentary layers were excavated in $3 \mathrm{~cm}$ arbitrary levels. All sediments were sieved through $2 \mathrm{~mm}$ mesh screens. Artifacts and bone specimens larger than $2.5 \mathrm{~cm}$, and natural rocks greater than $10 \mathrm{~cm}$ in maximum dimension, were piece-plotted in three dimensions. All items were recorded with a total station.

\subsection{Stratigraphy of Area A}

Stratigraphy is discussed briefly as it pertains to the taphonomic and zooarchaeological analyses (for a more detailed discussion, see Olszewski and al-Nahar, 2012). The complex stratigraphy of the 2012 excavation includes 13 natural layers (Fig. 4), only two of which (Layers 1 and 2) were present in all Area A excavation units and unit S97 (Table 1). Layer 1 was a surface layer that consisted of a pale brown, loose, disturbed topsoil (1-2 cm thick). Layer 2 consisted of a loose clay-silt sediment, with frequent gravel and pebble inclusions, and was most likely the parent sediment for Layer 1. Layer 2 varied between 3 and $15 \mathrm{~cm}$ thick in Area A, and between 28 and $45 \mathrm{~cm}$ thick in S97.

Six other layers were found in all or most excavation units in Area A (Table 1). Layer 3 (3$16 \mathrm{~cm}$ thick) consisted of a brown clay-silt sediment with a high concentration of cobbles and small boulders. Layer 4 (2-12 cm thick) consisted of a compact, dark grey, silty sediment. This layer was very hard and calcareous, most likely as a result of the percolation of dissolved calcium carbonate. Small chunks of calcium carbonate, and numerous cobbles and small boulders were dispersed throughout the layer. Layer 4c (2-6 cm thick) was looser than Layer 4, and consisted of a grey clay-silt sediment containing gravels and chunks of calcium carbonate.

Unit S97 contained only three layers - Layers 1 and 2 described above, and Layer 5b, which was unique to S97 and consisted of light brown, silty sediment with abundant gravels and some cobbles. Layer $5 \mathrm{~b}$ was around $12 \mathrm{~cm}$ thick at its maximum, and contained no bones.

Several additional layers occurred in various individual units in Area A (Table 1). These layers refer to small geological features (Layer 2a), ephemeral ashy deposits (Layers 4a, 4b, 5a), or off-color variations of previously defined natural layers (Layer 5c). Layers 1 and 2, and possibly Layers $4 \mathrm{a}$ and $4 \mathrm{~b}$, represent mixed contexts that included intrusive Neolithic arrowheads 
and other later period diagnostics mixed with Early Epipaleolithic materials. Because of their mixed origin, faunal specimens from Layers 1, 2, 4a, and $4 \mathrm{~b}$ are not included in this analysis.

\section{Analytical Methods}

Differential destruction of bones across different contexts at a site can alter their behavioral signatures and affect behavioral comparisons, since faunal assemblages from different contexts may experience unique taphonomic histories. A rigorous taphonomic inquiry should enable us to assess the nature of differential bone preservation, and the extent of its impact on behavioral markers of an assemblage.

Faunal specimens were identified to the most specific taxonomic category possible. If an element was identifiable but could not be assigned to at least the family level, it was categorized by body-size (i.e., small ungulate, medium bird). Bone portions and taphonomic characteristics were recorded for every identifiable specimen (Bar-Oz and Munro, 2004, Table 1; Stiner, 2004; Munro and Bar-Oz, 2005). We then grouped the data by occupational horizons, as defined above, and applied several analyses to reconstruct their taphonomic histories. We present the proportion of identified bones, the density of bones in the archaeological deposits (bone volume, bone-tolithic ratio), and measures of bone identifiability (proportions of identified specimens, \%identifiable). Assessment of the extent of fragmentation, fracture types, and inter-taxonomic comparisons allow us to identify the most likely or dominant taphonomic agent(s) responsible for overall preservation and differential destruction of bones in each horizon.

Analyses of human foraging behavior include relative taxonomic abundance, gazelle age profiles, and gazelle body-part representation. Relative taxonomic abundance is a measure of the proportion of high-ranked taxa to low-ranked taxa, and serves as a means to assess human encounter rates with high-ranked taxa on a regional scale. Our gazelle mortality profile examines the proportion of adult to juvenile gazelles in the assemblage. Because of small sample sizes, we examined gazelle mortality using a coarse measure - the percentage of fused long bones that fuse between the ages of 10-18 months. These specimens include the distal radius, proximal and distal ulna, proximal and distal femur, proximal tibia, tuber calcis of the calcaneum, and distal metapodials (Davis, 1980; Munro et al., 2009). Body part profiles present a systematic comparison of anatomical regions of a gazelle standardized against a complete skeletal model (Stiner, 1994, 2002). They reveal density-mediated patterns of differential destruction of certain 
anatomical regions. They further enable us to investigate human foraging behavior across the body of an animal. Equal distribution of all body parts suggests that foragers carried whole animals back to the site, which indicates lower incurred costs, such as shorter foraging distance. Differential distribution of body parts with high food utility is indicative of higher incurred costs, and selective processing of a carcass at the kill site.

\section{Results}

The total number of bones recovered from the Early Epipaleolithic deposits of the 2012 excavation totaled $13,213,75 \%(\mathrm{NSP}=9,927)$ of which were recovered from the lower horizon (Fig. 5a). Four percent of the total assemblage was identifiable to taxon, body-size category, and element, and again, most of these (70.1\%) derive from the lower horizon (Fig. 5b). However, a

slightly higher percentage of specimens from the upper horizon $(4.9 \%$; NISP $=377)$ were identifiable compared to the lower horizon (3.8\%; NISP=160) (Fig. 5c). The uneven distribution of identifiable and unidentifiable bones and the inverse relationship between NISP and identifiability in the two horizons despite nearly equal excavation volumes suggest that important differences in assemblage formation may have played a significant role in their preservation.

\subsection{Taphonomic Analysis of the Lower and Upper Horizons}

Similar quantities of sediment were excavated from the lower and upper horizons $\left(1.5 \mathrm{~m}^{3}\right.$ and $1.4 \mathrm{~m}^{3}$ respectively). However, significantly more bone per unit volume $\left(6500\right.$ specimens $\left./ \mathrm{m}^{3}\right)$ was recovered from the lower than the upper horizon $\left(1400\right.$ specimens $\left./ \mathrm{m}^{3}\right)$ (Fig. 5d). To determine if this is related to occupation intensity or preservation quality, the frequency of bones in each horizon was compared to the number of lithics. A similar difference exists-the lower horizon has a ratio of 0.75 bones per lithic, while the upper horizon yielded a ratio of only 0.4 (Fig. 5e). Although rates of deposition for bones and lithics could vary over time, such large differences in bone density and bone-to-lithic ratios in time-averaged deposits suggests that preservation biases have strongly impacted the distribution of bones in the two horizons.

The average length of all identified gazelle and small-sized ungulate specimens, excluding those with post-excavation breakage is small, indicating extensive fragmentation of the fauna (Table 2). The mean and median fragment lengths for 101 specimens from the lower horizon are $1.7 \mathrm{~cm}$ and $1.5 \mathrm{~cm}$ respectively. The same values for 23 specimens from the upper horizon are 
$1.9 \mathrm{~cm}$ and $2.0 \mathrm{~cm}$. The cause of fragmentation is identified by comparing the percentage of spiral to transverse fractures on gazelle long bones. Spiral fractures occur when a bone is broken while fresh, and is a good indication of anthropogenic processing of bones (Villa and Mahieu, 1991; Fisher, 1995). Transverse fractures occur after the collagen has decayed, most often after the bone has been deposited in the ground (Behrensmeyer, 1978). We identified no specimens with spiral or transverse fractures from the upper horizon, while $60 \%$ of the 10 specimens from the lower horizon exhibited spiral fractures (Fig. 5f). Most specimens from both horizons exhibited new fractures obtained during excavation, due to the fragility of specimens from the site. The spiral fractures from the lower horizon indicate that bones were fragmented to some extent before they were deposited in the archaeological record, where they were subject to even greater fragmentation that destroyed much of the original behavioral signal. The high rate of fragmentation, especially in the upper horizon, indicates that few, if any bones preserved humaninduced fracture patterns.

A final test of preservation quality examines the completeness of tortoise carapace elements in the two horizons. Although tortoise carapaces may be cracked open to extract the meat inside, the shell has no nutritional value and thus should not be subjected to intensive processing like gazelle limb bone shafts. Of the 48 carapace specimens in the lower horizon, 14.8\% (NISP=7) represent complete elements, compared to $4.3 \%(\mathrm{NISP}=5)$ of the 113 specimens from the upper horizon (Fig. 5g). The data suggest that post-depositional breakage occurred in both assemblages, but had a more profound impact on the upper horizon. This inverse relationship between NISP and \%completeness suggests that the higher identifiability noted earlier for the upper horizon (Fig. 5C) is a function of increased fragmentation. As fragmentation increases, NISP also increases, at least initially. Beyond a certain point, however, additional fragmentation will lower NISP values, as identifiable anatomical landmarks are broken beyond recognition (Binford, 1981; Marshall and Pilgrim, 1993). This threshold is higher for tortoise carapace elements, because their landmarks (flat surface and texture) are so diagnostic that they are identifiable even when fragmented. Therefore, similarity in the completeness of tortoise and gazelle specimens from the same horizon suggests that post-depositional processes affected taxa similarly within a single horizon. Differences in the tortoise specimen completeness between the two horizons however, suggest more intensive post-depositional destruction in the upper horizon. 
Together these analyses provide firm evidence that the preservation of the faunal assemblage was impacted by post-depositional processes throughout the excavation area. In some cases, these processes were severe enough to have obliterated signals of human bone processing. Importantly, all indications of preservation point to the same conclusion regarding the differential preservation of fauna from the upper and lower horizons. The lower density of faunal remains and bone-to-lithic ratios, along with higher fragmentation in the upper horizon, attest to better preservation in the lower horizon.

\subsection{Behavioral Analysis}

Relative taxonomic abundance reveals the dominance of gazelle and gazelle-sized small ungulates (most likely also gazelle) in both horizons. Equids and large ungulates compose the remaining 10 to $20 \%$ of the ungulates (Appendix 1; Fig. 6a and 6b). The contribution of other ungulates (e.g. boar and ibex) is negligible. Gazelle is the smallest ungulate taxon in these assemblages, making it the lowest-ranked ungulate species in terms of its net energetic return.

Because of small sample sizes, we examined the representation of juvenile gazelles using a coarse measure--the percentage of fused long bones that fuse between the ages of 10-18 months. Due to the small sample size, we combined the mortality data from both horizons. Unfused bones make up $8.3 \%$ of the 12 specimens in this category (Fig. $5 \mathrm{~h}$ ). In modern herds, gazelle age structure varies by season with higher proportions of juvenile gazelle in the spring - when fawns are born - than in the autumn and winter. The proportion of juveniles in a herd of mountain gazelle can vary between 23 to 39\% (Martin, 2000). Thus the proportion of juvenile gazelles at Tor-at Tareeq is much lower than expected even for the dry season, and clearly reflects a primedominated hunting strategy. The small game data also reveals that the site's inhabitants targeted higher-ranked slow-moving prey. Small game composes over two-thirds of the assemblage from both horizons (Fig. 6c), but this component is made up nearly entirely of tortoises, whose ease of collection ranks them higher than agile birds and hares (Fig. 6d). Only tortoise fragments larger than $1 \mathrm{~cm}$ are used here to reduce the impact of differential fragmentation.

Due to the upper horizon's small sample size, we combined gazelle body-part data from the two horizons to examine the relative representation of gazelle body-parts. We followed Stiner's (1994) method for calculating the body-part profile. The profile (Fig. 7) shows that lowerranked, high density elements of the feet and lower limbs are far better represented than elements 
with low structural density from the neck, and the axial skeleton, as well as higher-ranked elements from the upper limbs. Given the conditions of bone preservation, the absence of the neck and the axial skeleton are undoubtedly mediated by low bone density (Lyman, 1984, 1994). All other anatomical regions are relatively well represented, suggesting that carcasses were transported whole, which is not surprising given the small size of gazelle carcasses (ca 20-25 kg; Mendelssohn and Yom-Tov, 1999).

In summary, despite differences in the quality of preservation, the economic analysis reveals no significant differences between the two horizons. Evidence from both horizons shows that foragers primarily targeted ungulates, the highest ranked prey group, although most of these were the smallest-bodied ungulate (gazelle). Nevertheless, like all ungulates, gazelle are ranked higher than smaller prey in terms of net energetic return. Adult gazelles, which were preferentially targeted, are also ranked higher than juvenile individuals. Finally, of the small game taxa, the highest-ranked tortoises are by far the most abundant. The data thus indicate that these human foragers hunted efficiently throughout the Early Epipaleolithic period.

\section{Discussion}

Our taphonomic analysis revealed that faunal materials recovered from the lower and upper horizons in Area A are highly fragmented. The assemblage is small and in comparison to the lithic remains, overall recovery was low. Our analysis further suggested that post-depositional factors had modified or erased much of the original anthropogenic breakage of the assemblage. Faunal preservation is likely the result of diagenetic destruction. Diagenesis undermines the structural integrity of the bone, rendering it more susceptible to breakage by trampling or compaction (Gifford-Gonzalez, 1993; Lyman, 1994; Stiner, 1994; Kos, 2003; Munro and Bar$\mathrm{Oz}, 2005)$. The exact nature of diagenetic processes at the site is not clear. However, the differential patterns of bone destruction between the two horizons and our knowledge of the site's stratigraphy enable us to partially reconstruct site formation processes at Tor at-Tareeq.

The differences in preservation, recovery, and fragmentation between the two horizons correlate with major changes in the type of sediment. Layer 4, which represents the upper-most natural layer in the lower horizon, is composed of a calcreted sediment rich in percolated calcium carbonate. The layer has variable hardness and thickness, and covers all of the excavated units, except S97, in Area A (Fig. 8). We hypothesize that after its formation, the calcreted sediment at 
the top of Layer 4 served as a barrier that minimized, but did not entirely prevent, postdepositional processes like water percolation and trampling from harming the fauna in Layers 4, $4 \mathrm{c}, 5$, and 5c, which correspond to the lower horizon. High rates of fragmentation and overall low identifiability in both horizons may relate to the time at which Layer 4 became calcreted. The fauna in the lower horizon gradually accumulated for many years prior to the formation of the calcreted layer. Leading up to this time, sediments in the lower horizon would have been subject to trampling and other post-depositional processes. Once the breccia capping layer 4 formed, it protected the lower layers from subsequent post-depositional processes to which the upper horizon was more intensively exposed from the time of occupation until the present day.

The calcium carbonate that precipitated on top of Layer 4 undoubtedly derives from the dissolution of local limestone bedrock by percolating water from groundwater, springs, and/or precipitation (Kelts and Hsü, 1978; Reading, 1996, pp. 94). Clark et al. (1988) and Olszewski and al-Nahar (2012) noted possible prehistoric spring activity at Tor at-Tareeq. The presence of palustrine sediments in the site's matrix also suggests that the wetlands or a possible lake may be the agent of carbonate precipitation, though maximum lake levels may have been reached well before deposition of Layer 4 (Schuldenrein and Clark, 1994; Neeley et al., 2000). Further geoarchaeological and geomorphological analyses are necessary to test this hypothesis and to better understand the nature of Layer 4 and its role in mitigating bone preservation.

Differences in bone survivorship and destruction between the two horizons may hamper investigations of diachronic change in foraging intensity, especially between two periods with different climatic regimes. Taphonomic processes have altered or erased some of the finergrained anthropogenic markers, such as spiral fractures, though the identification of some spiral fractures in the lower horizon is a testament to relatively better preservation there. Taphonomic factors, especially dissolution, have differentially impacted bones according to their mineral density. However, post-depositional processes have not significantly altered broader behavioral signatures. In spite of significant differences in patterns of bone destruction and climatic setting between the two horizons, the uniformity of the results of our behavioral analysis between the two horizons suggest that the assemblage provides us with sound, broad behavioral signatures. Naturally, these markers are time-averaged and provide only a coarse-grained view of economic decision-making. 
The application of the prey choice model at a broad analytical scale conclusively demonstrates that relatively high-ranked taxa (large-bodied adult gazelles and easy-to-catch tortoises) dominate assemblages from both horizons. This provides strong support for high

foraging efficiency throughout the Early Epipaleolithic occupation of Tor at-Tareeq. Gazelles played a dominant role in the diet throughout the Levantine Epipaleolithic (Munro, 2004, 2009; Munro et al., this volume). Although large ungulates were likely hunted when encountered, the abundance of gazelles in the diet suggests that aurochs and equids were not that common on the landscape. Diets were thus widely supplemented with gazelles. These gazelles, which were most likely mountain gazelles (Gazella gazella), are not migratory (Martin, 2000) and would have enjoyed excellent forage in Wadi al-Hasa due to the pluvial and lacustrine conditions present during the Early Epipaleolithic. Relative to equids and aurochs, adult gazelles are small-bodied, and could have been carried by a single individual for up to several kilometers back to Tor atTareeq, as indicated by the body-part profile. On the other hand, Tortoises have small territories and can thrive in ecosystems disturbed by human occupation. Given their limited caloric returns, and to avoid high search and transport costs, tortoises are often captured in the vicinity of residential camps (Stiner and Munro, 2002). The emphasis on higher-ranked adult gazelle and slow-moving tortoises throughout the occupation suggest that local resources met the subsistence demands of the site's occupants in both periods.

All evidence suggests that foraging strategies remained quite stable throughout the site's Early Epipaleolithic occupation. Climatic amelioration during the formation of the upper horizon could have corresponded to lengthier visits to Tor at-Tareeq (Neeley et al., 1997, 1998, 2000; Olszewski and al-Nahar, 2012, 2014). Nevertheless, given the dominance of adult gazelles and tortoises in both horizons, any possible increase in population density and length of visits to Tor at-Tareeq was insufficient to deplete local resources, and thus, the scale of difference is not detectable in the faunal assemblage.

\section{Conclusion}

The relationship between human behavior and climatic fluctuations at the end of the Pleistocene are germane to any investigation of Epipaleolithic adaptations in semi-arid environments. This is especially true given the scale of climatic change associated with the Last Glacial Maximum and after. This discussion, however, is impacted by the fact that many Early 
Epipaleolithic sites in the western highlands of Jordan suffer from poor faunal preservation. Differential destruction of bones across different contexts at a site can alter the behavioral signature of bones necessary for comparative behavioral assessments, since faunal assemblages from different contexts may undergo unique taphonomic histories.

The site of Tor at-Tareeq, and its two time-averaged Early Epipaleolithic horizons provided a unique opportunity to apply a rigorous taphonomic analysis to investigate the impact of differential destruction of bones in different contexts on analyses of change in human behavior through time. Our taphonomic inquiry allowed us to better understand the nature and pattern of bone destruction in each horizon, and to determine the dominant agents of destruction. Additionally, our taphonomic and behavioral analyses allowed us to rule out differential destruction as a modifier of broader behavioral signatures from each horizon.

Despite the influence of post-depositional processes, it was possible to provide a broad behavioral assessment of the small faunal assemblage from Tor at-Tareeq. In spite of differences in preservation between the two Early Epipaleolithic horizons and differences in climatic regime throughout the site's Early Epipaleolithic occupation, we argue that at no point was population density and site occupation intensity high enough to stress local resources in the site's vicinity.

\section{Acknowledgments}

This research was supported by a National Science Foundation (NSF) grant (\#SBR-9618766) to Nancy R. Coinman and Deborah I. Olszewski, and an NSF grant (\#0917660) to Deborah I. Olszewski and Maysoon al-Nahar. Additional funding was provided to Siavash Samei by the Summer Research Fund of the University of Connecticut's Anthropology Department. Logistical assistance was provided by the University of Jordan and Hashemite University. Thanks to the Jordanian Department of Antiquities for enabling the export of the faunal remains for study in the United States. We also thank many student volunteers from Jordan and the United States who made the excavations possible. This is WHEEP Contribution \#11.

Appendix 1: Number of identified specimens (NISP) of taxa represented in the upper and lower horizons of the Early Epipaleolithic occupation at Tor at-Tareeq. 


\begin{tabular}{|c|c|c|c|c|c|c|c|}
\hline \multicolumn{2}{|c|}{ Taxon } & \multicolumn{2}{|c|}{$\begin{array}{c}\text { LOWER } \\
\text { horizon }\end{array}$} & \multicolumn{2}{|c|}{$\begin{array}{l}\text { UPPER } \\
\text { horizon }\end{array}$} & \multicolumn{2}{|c|}{ Combined } \\
\hline Common Name & Latin Name & NISP & $\%$ & NISP & $\%$ & NISP & $\%$ \\
\hline Tortoise & Testudo graeca & 199 & 52.8 & 120 & 75.0 & 319 & 59.4 \\
\hline Small Bird & & 0 & 0.0 & 1 & 0.6 & 1 & 0.2 \\
\hline Medium Bird & & 4 & 1.1 & 2 & 1.3 & 6 & 1.1 \\
\hline Large Bird & & 1 & 0.3 & 0 & 0.0 & 1 & 0.2 \\
\hline Falconiforme & Falconiformes & 2 & 0.5 & 0 & 0.0 & 2 & 0.4 \\
\hline $\begin{array}{l}\text { Small Perching } \\
\text { Bird }\end{array}$ & Passeriformes & 1 & 0.3 & 0 & 0.0 & 1 & 0.2 \\
\hline Hare & Lepus capensis & 9 & 2.4 & 1 & 0.6 & 10 & 1.9 \\
\hline Wild Ass & Equus hemionus & 16 & 4.2 & 4 & 2.5 & 20 & 3.7 \\
\hline Aurochs & Bos primigenius & 1 & 0.3 & 2 & 1.3 & 3 & 0.6 \\
\hline Goat & Capra aegagrus & 1 & 0.3 & 0 & 0.0 & 1 & 0.2 \\
\hline Gazelle & Gazella sp. & 78 & 20.7 & 22 & 13.8 & 100 & 18.6 \\
\hline Small Ungulate & & 49 & 13.0 & 4 & 2.5 & 53 & 9.9 \\
\hline Medium Ungulate & & 3 & 0.8 & 0 & 0.0 & 3 & 0.6 \\
\hline Large Ungulate & & 6 & 1.6 & 3 & 1.9 & 9 & 1.7 \\
\hline Huge Ungulate & & 1 & 0.3 & 0 & 0.0 & 1 & 0.2 \\
\hline Dog Family & Canidae & 0 & 0.0 & 1 & 0.6 & 1 & 0.2 \\
\hline Fox & Vulpes vulpes & 3 & 0.8 & 0 & 0.0 & 3 & 0.6 \\
\hline Small Mammal & & 1 & 0.3 & 0 & 0.0 & 1 & 0.2 \\
\hline Medium Mammal & & 2 & 0.5 & 0 & 0.0 & 2 & 0.4 \\
\hline & & 377 & & 160 & & 537 & \\
\hline
\end{tabular}

\section{References}

Bar-Oz, G., Munro, N.D., 2004. Beyond cautionary tales: a multivariate taphonomic approach for resolving equifinality in zooarchaeological studies. Journal of Taphonomy 4, 201-222.

Bar-Yosef, O., 1990. The Last Glacial Maximum. In: Gamble, C., Soffer, O. (Eds.), The World at 18,000 b.p, Vol. 2: Low Latitudes. Unwin Hyman, London, pp. 58-77.

Behrensmeyer, A.K., 1978. Taphonomic and ecological information from bone weathering. Paleobiology 4, 150-162.

Binford, L.R., 1981. Bones: Ancient Men and Modern Myths. Academic Press, New York. 
Broughton, J.M., 1994. Declines in mammalian foraging efficiency during the Late Holocene, San Francisco Bay, California. Journal of Anthropological Archaeology 13, 371-401.

Broughton, J.M., Cannon, M.D., Bayham, F.E., Byers, D.A., 2011. Prey body size and ranking in zooarchaeology: theory, empirical evidence, and applications from the northern Great Basin. American Antiquity 76 (3), 403-428.

Byrd, B.F., Garrard, A.N., 1990. The Last Glacial Maximum in the Jordanian Desert. In: Gamble, C., Soffer, O. (Eds.), The World at 18,000 b.p, Vol. 2: Low Latitudes. Unwin Hyman, London, pp. 78.96.

Charnov, E.L., 1976, Optimal foraging: the marginal value. Theoretical Population Biology 9, 129-136.

Clark, G.A., Lindley, J.H., Donaldson, M., Garrard, A., Coinman, N., Schuldenrein, J., Fish, S., Olszewski, D.I., 1987. Paleolithic archaeology in the southern Levant: A preliminary report of excavations at Middle, Upper and Epipaleolithic Sites in Wadi el-Hasa, west-central Jordan. Annual of the Department of Antiquities of Jordan 31, 19-78.

Clark, G.A., Lindley, J.H., Donaldson, M., Garrard, A., Coinman, N., Schuldenrein, J., Fish, S., Olszewski, D.I., 1988. Excavation at Middle, Upper and Epipaleolithic sites in Wadi Hasa, west-central Jordan. In: Garrard, A.N., Gebel, H.G. (Eds.), The Prehistory of Jordan: The State of Research in 1986. British Archaeological Reports International Series 396, Oxford, pp. 209-285.

Clark, G.A., Neeley, M., MacDonald, B., Schuldenrein, J., 'Amr, K., 1992. Wadi Hasa Paleolithic Project - 1992: preliminary report. Annual of the Department of Antiquities of Jordan 36, 13-23.

Davis, S.J., 1980. A note on the dental and skeletal ontogeny of Gazella. Israel Journal of Zoology 29, 129-134.

Fisher, J.W., 1995. Bone surface modifications in zooarchaeology. Journal of Archaeological Method and Theory 2 (1), 7-68.

Flannery, K.V., 1969. Origins and ecological effects of early domestication in Iran and the Near East. In: Ucko, P.J., Dimbleby, G.W. (Eds.), The Domestication and Exploitation of Plants and Animals. Aldine, Chicago, pp. 73-100.

Gifford-Gonzalez, D.P., 1993. Gaps in ethnoarchaeological research on bone. In: Judson, J. (Ed.), From Bones to Behavior: Ethnoarchaeological and Experimental Contributions to the 
Interpretation of Faunal Remains, Occasional Paper No. 21, Center for Archaeological Investigations. Southern Illinois University, Carbondale, IL, pp. 181-199.

Hames, R.B., 1980. Game depletion and $\mathrm{h}$ nting zone rotation among the Ye'kwana and Yanomam of Amazonas, Venezuela. In: Hames, R.B. (Ed.), Studies in hunting and fishing in the Neotropics. Bennington College Working Papers on South American Indians 2, Bennington, VT, pp. 31-66.

Henry, D.O., 1997. Prehistoric human ecology in the Southern Levant east of the Rift from 20,000-6 000 BP. Paléorient 23 (2), 107-119.

Kelts, K., Hsü, K.J., 1978. Freshwater carbonate sedimentation. In: Lerman, A. (Ed.), Lakes: Chemistry, Geology, Physics. Springer-Verlag, Berlin, pp. 295-323.

Kos, A.M., 2003. Characterisation of post-depositional taphonomic processes in the accumulation of mammals in a pitfall cave deposit from southeastern Australia. Journal of Archaeological Science 30 (6), 781-796.

Kuhn, S.L., Arsebük, G., Clark Howell, F., 1996. The Middle Pleistocene lithic assemblage from Yarimburgaz Cave, Turkey. Paléorient 22 (1), 31-49.

Lupo, K.D., 2007. Evolutionary foraging models in zooarchaeological analysis: recent applications and future challenges. Journal of Archaeological Research 15, 143-189.

Lyman, R.L., 1984. Bone density and differential survivorship of fossil classes. Journal of Anthropological Archaeology 3, 259-299.

Lyman, R.L., 1994. Vertebrate Taphonomy. Cambridge University Press, Cambridge.

MacArthur, R.H., Pianka, E.R., 1966. On optimal use of a patchy environment. The American Naturalist 100 (916), 603-609.

MacDonald, B., Rollefson, G.O., Banning, E.B., Byrd, B.F., D'Annibale, C., 1983. The Wadi alHasa archaeological survey 1982: a preliminary report. Annual of the Department of Antiquities of Jordan 27, 311-323.

Marshall, F., Pilgrim, T., 1993. NISP vs. MNI quantification of body-part representation. American Antiquity 58 (2), 261-269.

Martin, L., 2000. Gazelle (Gazella spp.) Behavioural ecology: predicting animal behaviour for prehistoric environment in south-west Asia. Journal of Zoology 250, 13-30.

Mendelssohn, H., Yom-Tov, Y., 1999. Fauna Palaestina: Mammalia of Israel. Israel Academy of Sciences and Humanities, Jerusalem. 
Muheisen, M., 1988. The Epipaleolithic phases of Khareneh IV. In: Garrard, A.N., Gebe, H.G. (Eds.), The Prehistory of Jordan: The State of Research in 1986 British Archaeological Reports International Series 396 (ii), Oxford, pp. 353-367.

Munro, N.D., 2004. Zooarchaeological measures of hunting pressure and occupation intensity in the Natufian: implications for agricultural origins. Current Anthropology 45, S5-S33.

Munro, N.D., 2009. Epipaleolithic subsistence intensification in the southern Levant: the faunal evidence. In: Hublin, J.-J., Richards, M.P. (Eds.), The Evolution of Hominin Diets: Integrating Approaches to the Study of Palaeolithic Subsistence. Springer, Leipzig, pp. 141155.

Munro, N.D., Bar-Oz, G., 2005. Gazelle bone fat processing in the Levantine Epipalaeolithic. Journal of Archaeological Science 32, 223-239.

Munro, N.D., Bar-Oz, G., Stutz, A., 2009. Aging mountain gazelle (Gazella gazella): refining methods of tooth eruption and wear and bone fusion. Journal of Archaeological Science 36, 752-763.

Nadel, D., Hershkovitz, I., 1991. Subsistence data and human remains from the earliest Levantine Epipalaeolithic. Current Anthropology 32 (5), 631-635.

Nagaoka, L., 2001. Using diversity indices to measure changes in prey choice at the Shag River Mouth Site, southern New Zealand. International Journal of Osteoarchaeology 11, 101-111.

Neeley, M.P., Clark, G.A., Schuldenrein, J., Peterson, J.D., 1997. WHS 1065 (Tor at-Tariq): an Epipaleolithic site in its regional context. Studies in the History Archaeology of Jordan 6, 219-225.

Neeley, M.P., Peterson, J.D., Clark, G.A., Fish, S.K., 2000. WHS 1065 (Tor al-Tareeq): an Epipaleolithic site in the Wadi al-Hasa, west-central Jordan. In: Coinman, N.R. (Ed.) The Archaeology of the Wadi al-Hasa, West-Central Jordan, Vol. 2: Excavations and Research at Middle, Upper and Epipaleolithic Sites, Anthropological Research Papers. Arizona State University, Tempe, AZ, pp. 245-279.

Neeley, M.P., Peterson, J.D., Clark, G.A., Fish, S.K., Glass, M., 1998. Investigations at Tor alTareeq: an Epipaleolithic Site in the Wadi el-Hasa, Jordan. Journal of Field Archaeology 25 (3), 295-317.

Olszewski, D.I., al-Nahar, M., 2012. Excavations in Area A at Tor at-Tareeq (WHS 1065), Wadi al-Hasa, Summer 2012. Unpublished Report to the Department of Antiquities of Jordan. 
Olszewski, D.I., al-Nahar, M., 2014. The 2012 excavations in the Area A Early Epipaleolithic at Tor at-Tareeq, Wadi al-Hasa. Neo-Lithics 1 (14), 25-32.

Olszewski, D.I., Coinman, N.R., Clausen, T.G., Cooper, J.B., Jansson, H., al-Nahar, M., Schurmans, U., Saele, L.S., Sampson, A.J., Thompson, J.R., 2001. The Eastern Hasa Late Pleistocene Project: preliminary report on the 2000 field season. Annual of the Department of Antiquities of Jordan 45, 39-60.

Olszewski, D.I., Cooper, J.B., Jansson, H., Schurmans, U., 2000. A third season of excavations at Tor al-Tareeq (WHS 1065), an Early and Middle Epipaleolithic site in the Wadi al-Hasa, Jordan. Neo-Lithics 2-3, 14-16.

Olszewski, D.I., Munro, N.D., Kennerty, M. In Press. The Middle Epipaleolithic at Tor at-Tareeq in the Wadi al-Hasa, Jordan. In: M. Neeley, G.A. Clark, and M. Daviau (Eds.), Walking Through Jordan: Essays in Honor of Burton MacDonald. Sheffield: Equinox Publishing.

Olszewski, D.I., Schurmans, U., 2007. Raw material use in west-central Jordan. In: Delage, C. (Ed.) Chert Availability and Prehistoric Exploitation in the Near East. British Archaeological Reports International Series S1615, Oxford, pp. 164-203.

Reading, H.G., 1996. Sedimentary Environments: Processes, Facies, and Stratigraphy. Backwell Science, Malden, MA.

Schuldenrein, J., Clark, G.A., 1994, Landscape and prehistoric chronology of west-central Jordan. Geoarchaeology 9, 31-55.

Schuldenrein, J., Clark, G.A., 2001. Prehistoric landscapes and settlement geography along the Wadi Hasa, west-central Jordan. Part I: geoarchaeology, human palaeoecology and ethnographic modeling. Environmental Archaeology 6, 23-38.

Stephens, D.W., Krebs, J.R., 1986. Foraging Theory. Princeton University Press, Princeton.

Stiner, M.C., 1994. Honor among Thieves: A Zooarchaeological Study of Neanderthal Ecology. Princeton University Press: Princeton.

Stiner, M.C., 2001. Thirty years on the "broad spectrum revolution" and Paleolithic demography. Proceedings of the National Academy of Sciences 98 (31), 6993-6996.

Stiner, M.C., 2002. On in situ attrition and vertebrate body part profiles. Journal of Archaeological Science 29, 979-991.

Stiner, M.C., 2004. A comparison of photon densitometry and computed tomography parameters of bone density in ungulate body part profiles. Journal of Taphonomy 2 (3), 117-146. 
Stiner, M.C., 2005. The Faunas of Hayonim Cave, Israel: A 200,000-Year Record of Paleolithic Diet, Demography, and Society. Peabody Museum Press, Cambridge, MA.

Stiner, M.C., Munro, N.D., 2002. Approaches to prehistoric diet breadth, demography, and prey ranking systems in time and space. Journal of Archaeological Method and Theory 9 (2), 181-214.

Stutz, A.J., Munro, N.D., Bar-Oz, G., 2009. Increasing the resolution of the broad spectrum revolution in the southern Levantine Epipaleolithic (19-12 ka). Journal of Anthropological Archaeology 56, 294-306.

Stiner, M.C., Munro, N.D., Surovell, T.A., 2000. The tortoise and the hare: small-game use, the broad-spectrum revolution, and Paleolithic demography. Current Anthropology 41, 39-79.

Stiner, M.C., Munro, N.D., Surovell, T.A., Tchernov, E., Bar-Yosef, O., 1999. Paleolithic population growth pulses evidenced by small animal exploitation. Science 283, 190-194.

Tchernov, E., 1993. The impact of sedentism on animal exploitation in the southern Levant. In: Buitenhuis, H., Clason, A.T. (Eds.) Archaeozoology of the Near East. Universal Book Service, Leiden, pp. 10-26.

Villa, P., Mahieu, E., 1991. Breakage patterns of human long bones. Journal of Human Evolution 21, 27-48.

Vita-Finzi, C., 1966. The Hasa Formation: an alluvial deposition in Jordan. Man 1 (3), 386-390.

Weiss, E., Kislev, M.E., Simchoni, O., Nadel, D., 2004. Small-grained wild grasses as staple food at the 23 000-year-old site of Ohalo II, Israel. Economic Botany 58, S125-S134.

Winer, E.R., 2010. Interpretation and Significance of Late Quaternary Valley-Infill Deposits in Wadi Hasa, West-Central Jordan. Unpublished M.S. thesis. Department of Geology, Miami University, Oxford, $\mathrm{OH}$.

Winterhalder, B., 1986. Diet choice, risk, and food sharing in a stochastic environment. Journal of Anthropological Archaeology 5, 369-392.

Winterhalder, B., Smith, E.A., 2000. Analyzing adaptive strategies: human behavioral ecology at twenty-five. Evolutionary Anthropology 9 (2), 51-72.

\section{Figure Captions}

Fig. 1. Geographic location of Tor at-Tareeq (WHS1065). Wadi al-Hasa is clearly visible to the west of the site. 
Fig. 2. A view of the 2012 excavations at Tor at-Tareeq; limestone bedrock and sediments from Pleistocene "Lake Hasa" can be seen at the top of the image. Photo modified from Olszewski and al-Nahar (2012).

Fig. 3. Topographic map of Tor at-Tareeq indicating the location of major excavation units (each grid unit $=1 \mathrm{~m}^{2}$ ). Black dots and letters $\mathrm{P}$ and $\mathrm{G}$ at the top of the map refer to bedrock mortars, petroglyphs, and game boards respectively. Map modified from Olszewski and al-Nahar (2012).

Fig. 4. Stratigraphy of the southern profile of excavation units M97 and L97 in Area A. Photo modified from Olszewski and al-Nahar (2012).

Fig. 5. Taphonomic analyses of fauna from each occupational horizon; NSP=total number of specimens recovered, including both identifiable and unidentifiable specimens, NISP $=$ number of identifiable specimens; all NSP values refer to fragments larger than $25 \mathrm{~mm}$ :

(a) proportion of all recovered fragments.

(b) proportion of identifiable specimens from each horizon relative to the total NISP.

(c) proportion of identifiable specimens in each horizon's assemblage.

(d) amount of bone recovered relative to sediment volume removed.

(e) proportion of bones to lithics, which include all technological classes larger than $25 \mathrm{~mm}$; lithic values are after al-Nahar and Olszewski (this volume), though differ slightly from those values due to the analytical categories used; detailed information on lithic density for each horizon is also provided by Olszewski and al-Nahar, this volume.

(f) proportion of specimens with spiral fractures, calculated out of the total number of specimens exhibiting spiral or transverse fractures, excluding specimens with new, post excavation fractures. 
(g) proportion of complete tortoise carapace fragments, excluding specimens with new, post excavation fractures.

(h) proportion of unfused/fusing and fused gazelle specimens, after Munro et al. (2009).

Fig. 6. Relative taxonomic abundance indices:

(a) index of major ungulate species; including gazelle (back), aurochs (dark grey), equids (white), and ibex (light grey).

(b) index of ungulates by body size; including small ungulates like gazelles (black), medium ungulates like ibex and boar (dark grey), large ungulates like equids (white), and huge ungulates like aurochs (light grey).

(c) index of major classes of prey; including ungulates (black), carnivores (white), and small game (grey); tortoise fragments exclude specimens smaller than $10 \mathrm{~mm}$.

(d) index of major classes of small game; including tortoises (black), birds (white), and hares (grey); tortoise fragments exclude specimens smaller than $10 \mathrm{~mm}$.

Fig. 7. Gazelle body part profile; based on the percent of minimum number of elements (\%MNE); "n” values refer to NISP. Constructed following Stiner (1994).

Fig. 8. Calcreted surface of Layer 4 in excavation units L97 and L98. Photo taken by Deborah Olszewski. 


\section{Table 1}

Relative position of natural layers in the 2012 excavation units. Table modified after Olszewski and al-Nahar (2012). *

\begin{tabular}{|ccccccccccc|}
\hline L97 & M97 & I98 & J98 & L98 & M98 & I99 & J99 & L99 & M99 & S97 \\
\hline 1 & 1 & 1 & 1 & 1 & 1 & 1 & 1 & 1 & 1 & 1 \\
2 & 2 & 2 & 2 & 2 & 2 & 2 & 2 & 2 & 2 & 2 \\
- & - & - & - & - & - & $2 \mathrm{a}$ & - & - & - & - \\
- & $4 \mathrm{a}$ & - & - & - & - & - & - & - & - & - \\
- & $4 \mathrm{~b}$ & - & - & - & - & - & - & - & - & - \\
3 & 3 & 3 & 3 & 3 & 3 & 3 & 3 & 3 & 3 & - \\
4 & 4 & 4 & 4 & 4 & 4 & 4 & 4 & 4 & 4 & - \\
$4 \mathrm{c}$ & $4 \mathrm{c}$ & $4 \mathrm{c}$ & $4 \mathrm{c}$ & $4 \mathrm{c}$ & - & - & $4 \mathrm{c}$ & - & - & - \\
5 & 5 & 5 & 5 & 5 & 5 & 5 & 5 & 5 & 5 & - \\
$4 \mathrm{~d}$ & - & - & - & $4 \mathrm{~d}$ & - & - & - & - & - & - \\
$5 \mathrm{a}$ & - & - & - & - & - & - & - & - & - & - \\
- & - & - & - & - & - & - & - & - & - & $5 \mathrm{~b}$ \\
$5 \mathrm{c}$ & $5 \mathrm{c}$ & $5 \mathrm{c}$ & - & - & - & - & - & - & - & - \\
\hline
\end{tabular}

* Units K97, K98, and K99 refer to small amounts of mixed sediments along the collapsed profile of Trench A from the 1984 excavations, and so they are not included in this study. The broad characteristics of each layer is as follows:

Layers 1 and 2: surface material and/or mixed contexts, excluded from this study Layer 2a: geological feature, no bones

Layers $4 \mathrm{a}$ and $4 \mathrm{~b}$ : mixed contexts, excluded from this study

Layer 3: UPPER horizon

Layers 4, 4c, 5, and 5c: LOWER horizon

Layers $4 \mathrm{~d}$ and $5 \mathrm{~b}$ : no bones 


\section{Table 2}

Greatest length of all gazelle and small ungulate specimens (in $\mathrm{cm}$ ); excluding specimens with new, post-excavation fractures.

\begin{tabular}{|lllll|}
\hline Occupational Horizons & NISP & Mean & Median & SD \\
\hline UPPER & 23 & 1.50 & 2.00 & 0.14 \\
LOWER & 101 & 1.69 & 1.94 & 0.76 \\
\hline
\end{tabular}




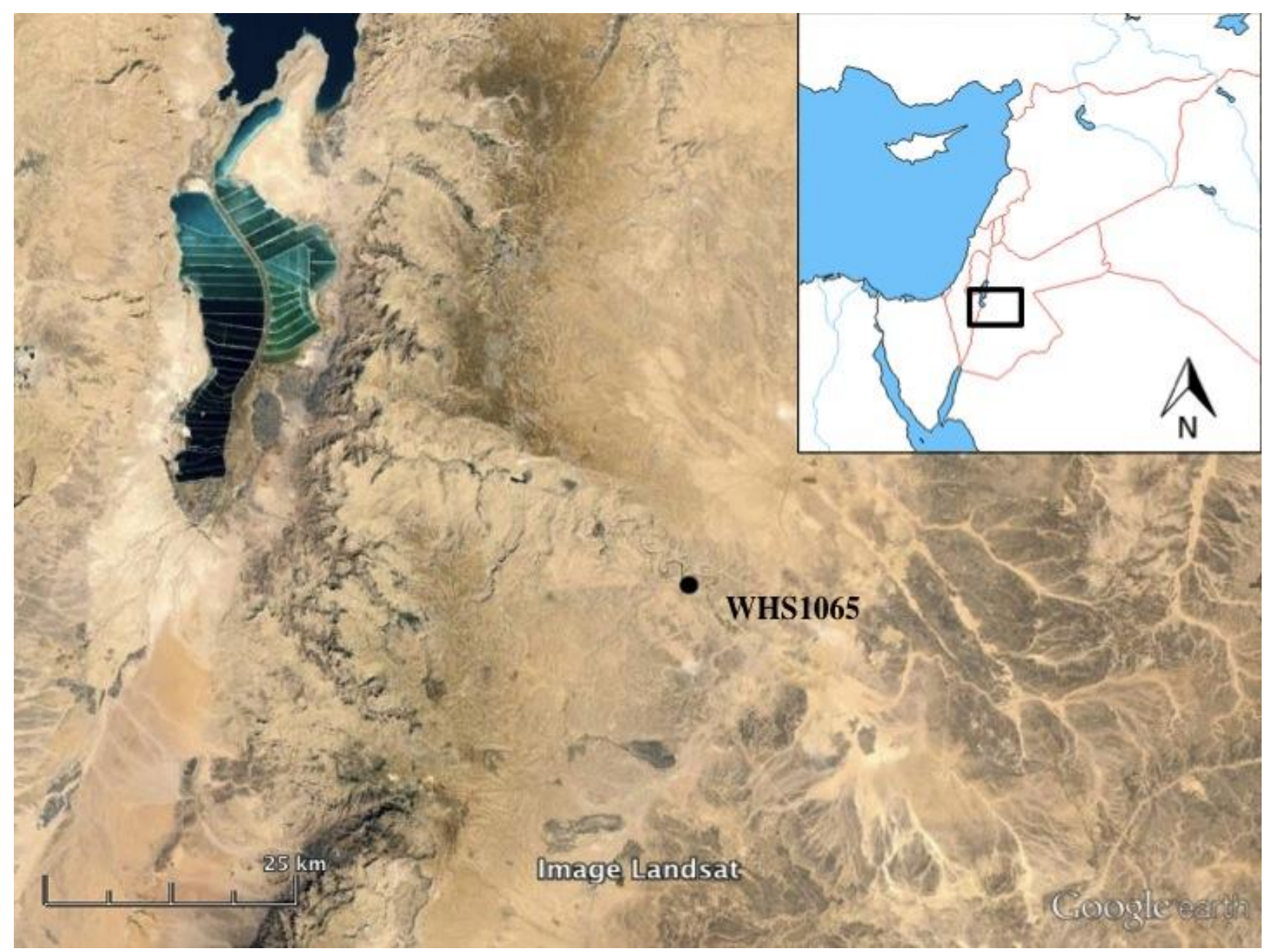

Figure 1 


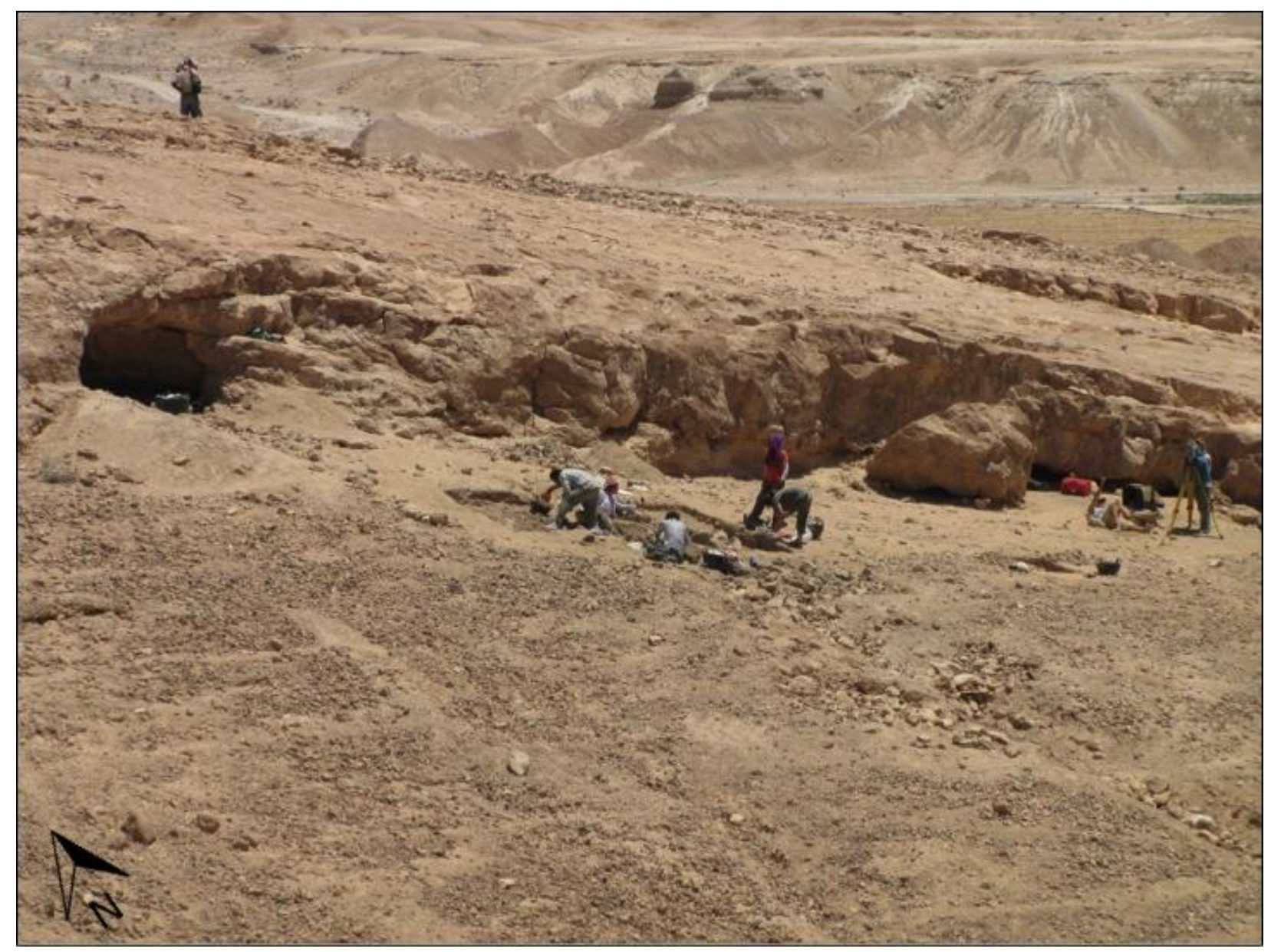

Figure 2 


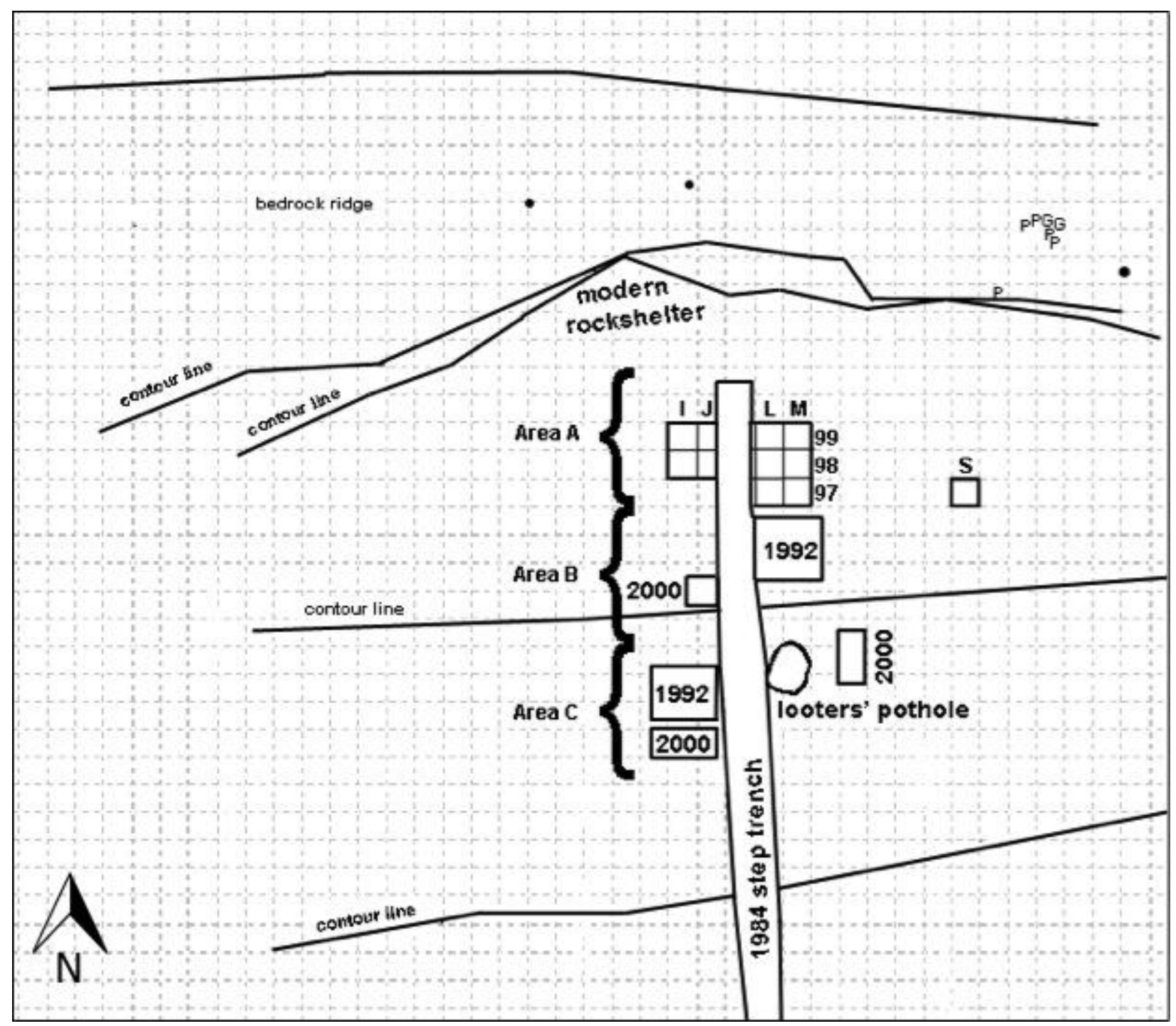

Figure 3 


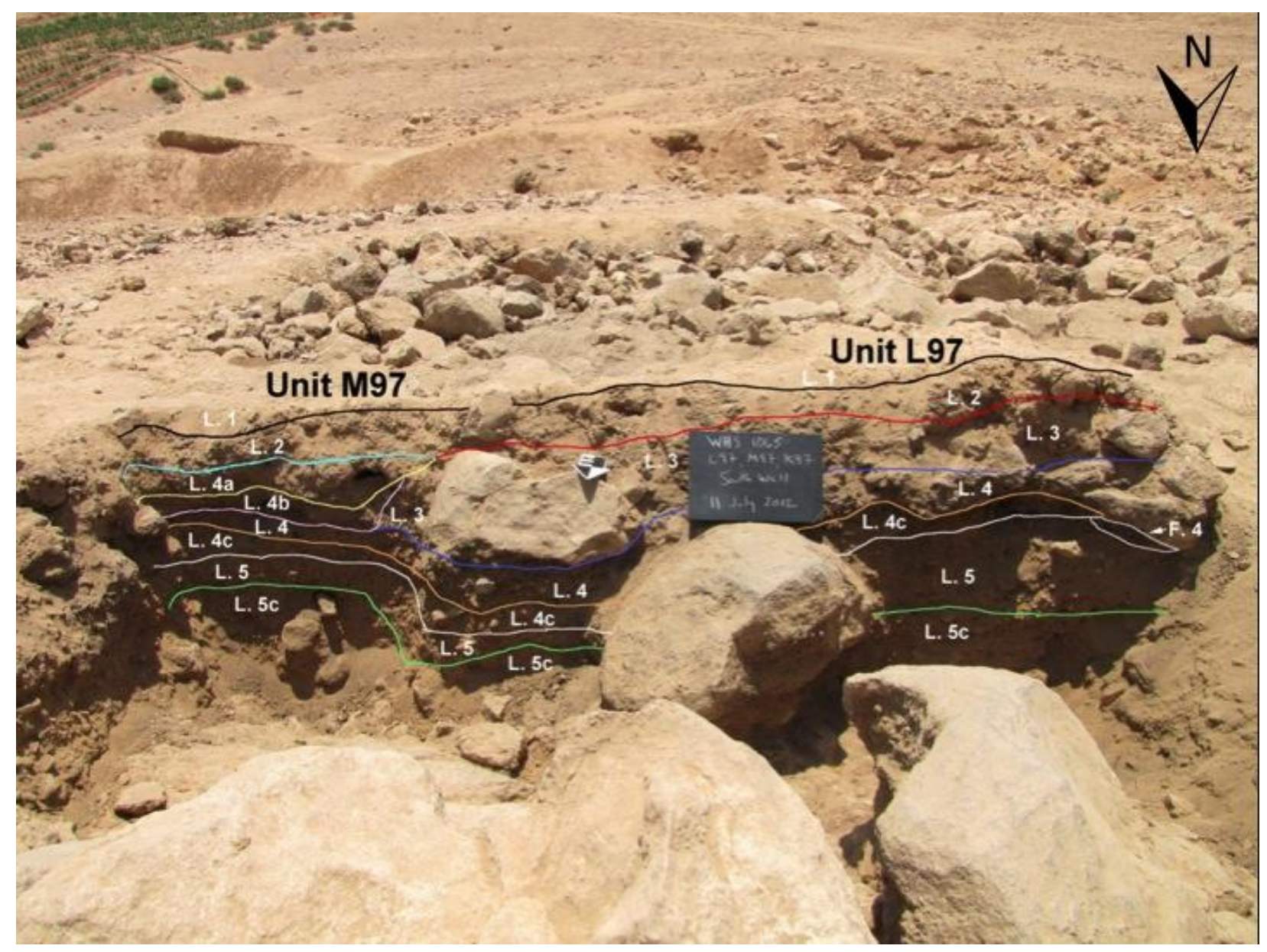

Figure 4 


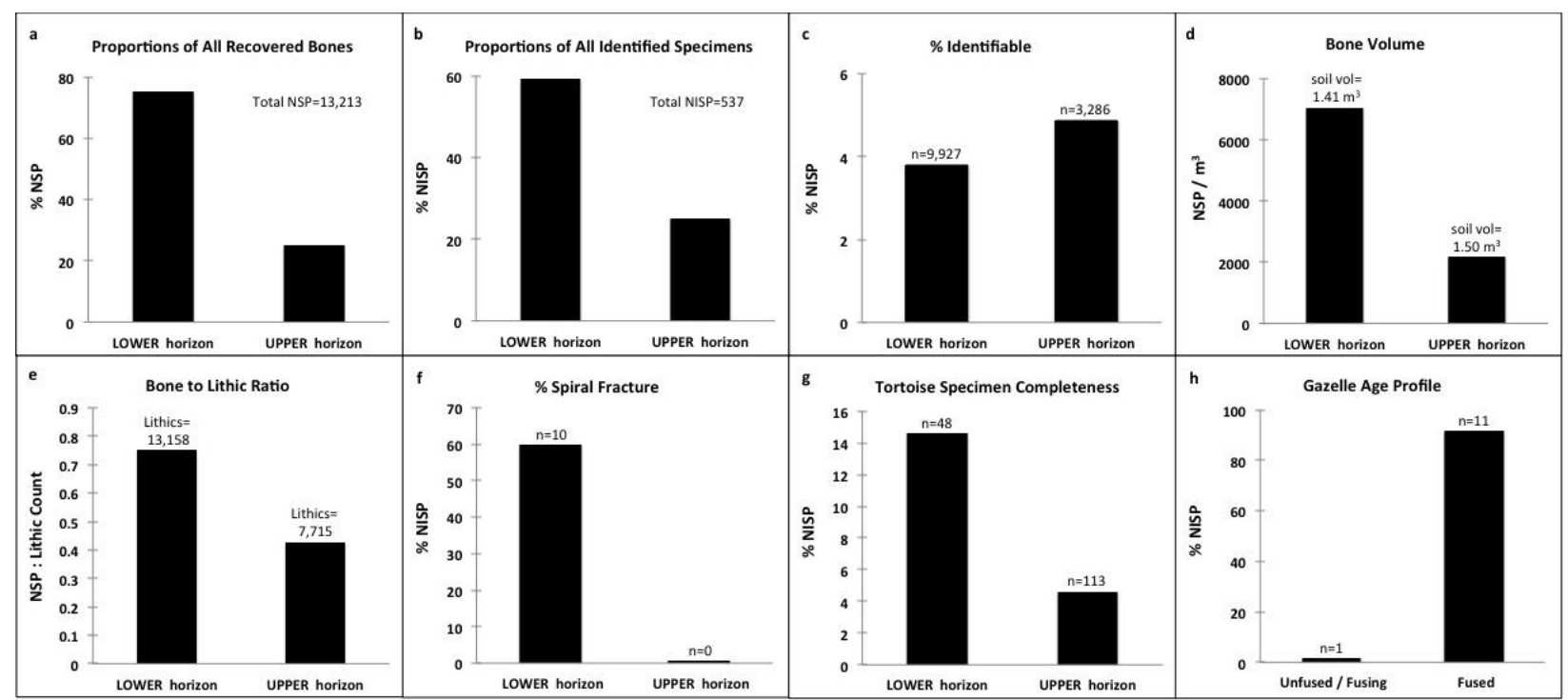

Figure 5 


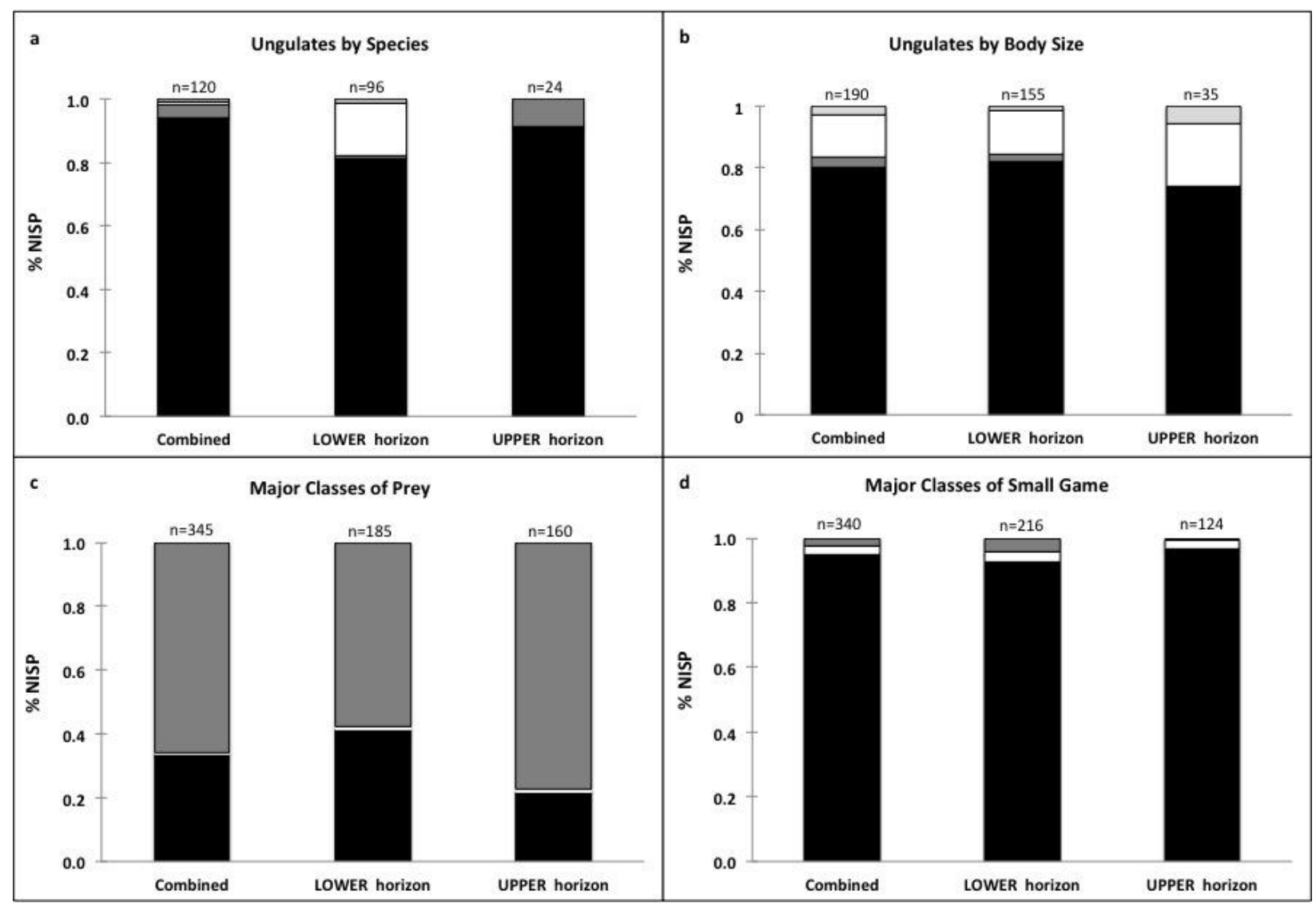

Figure 6 


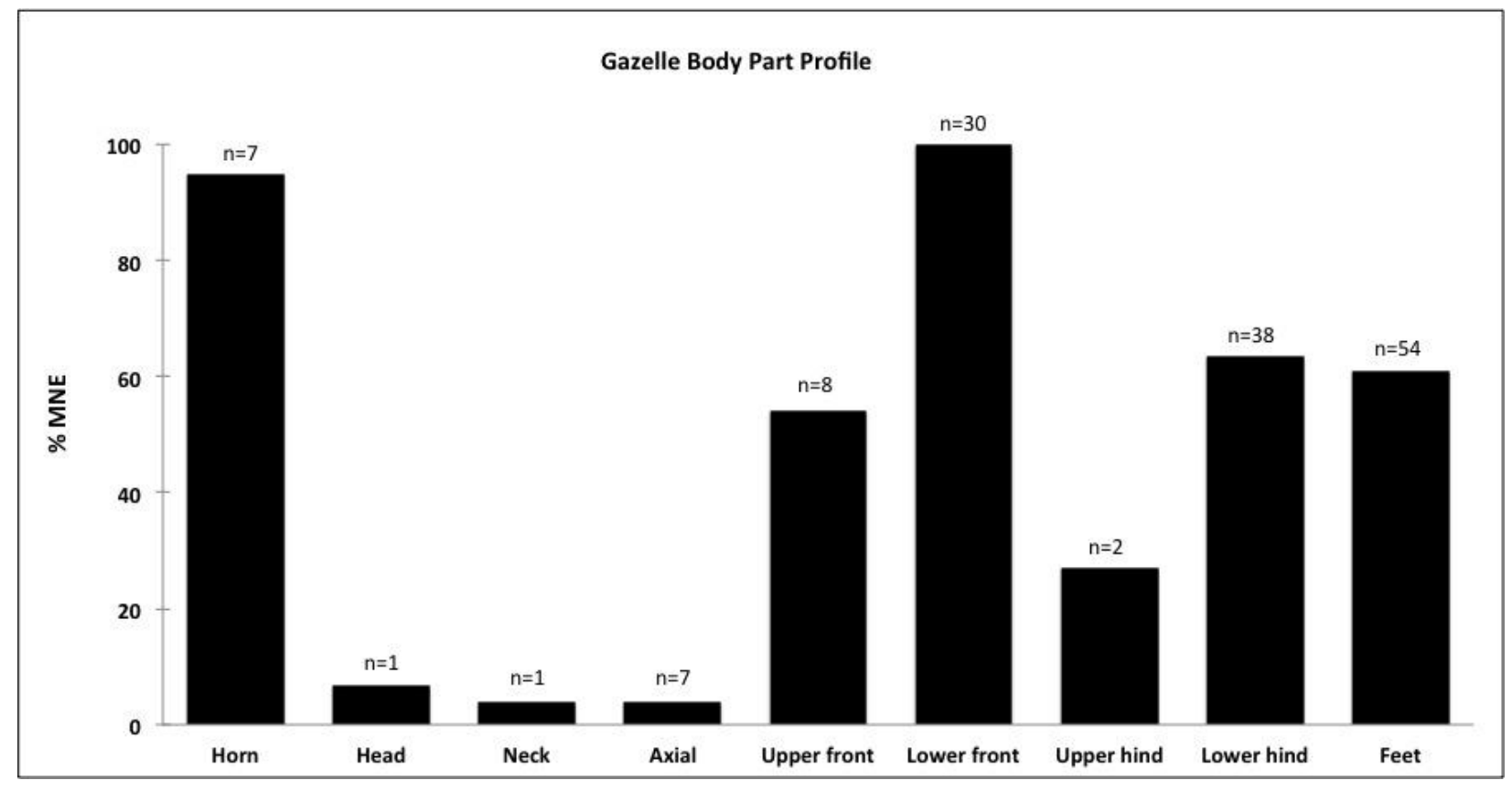

Figure 7 


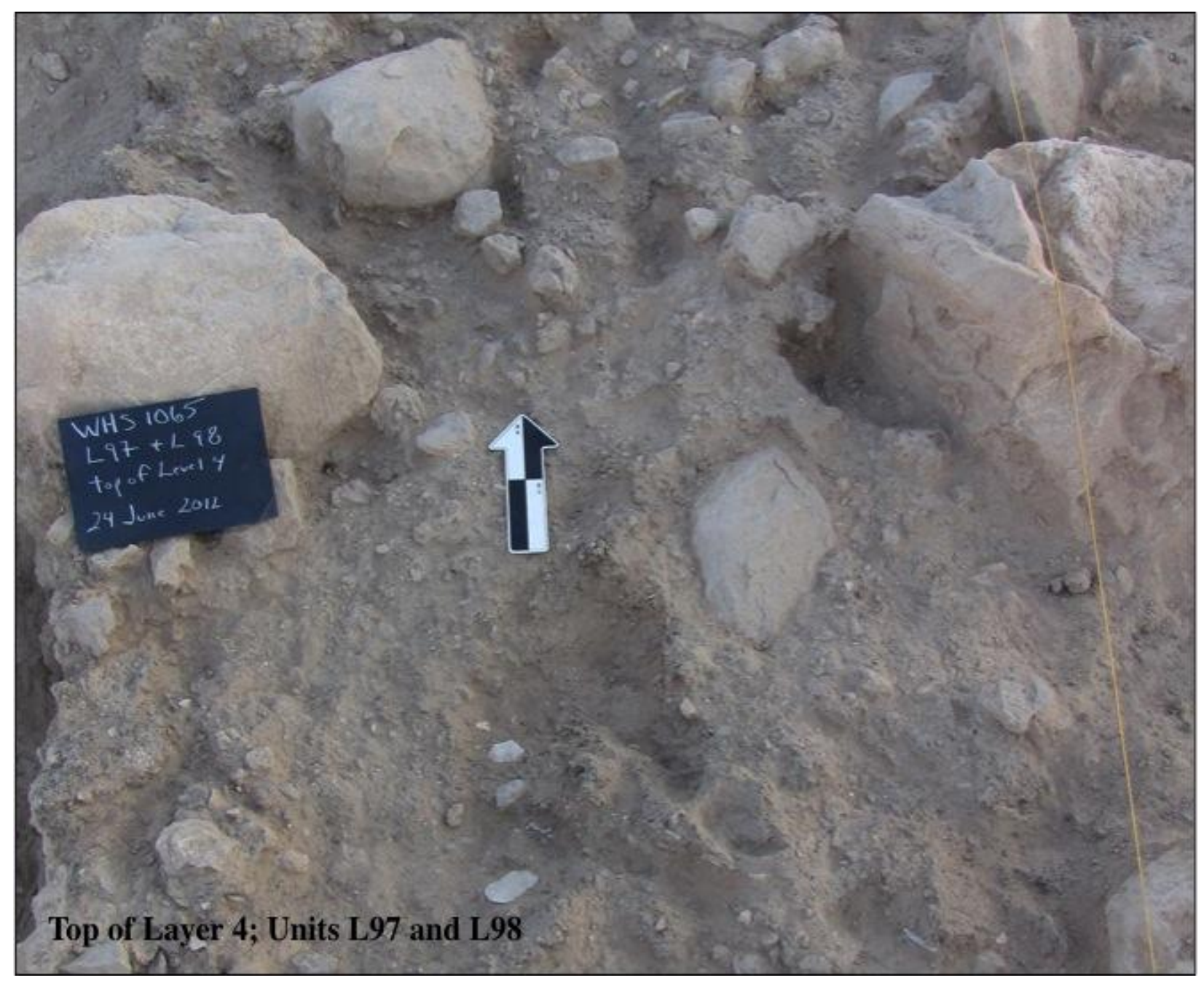

Figure 8 